\title{
Typhoid ulcer related massive gastrointestinal bleeding successfully treated with endoscopic therapy
}

\author{
Amey D. Sonavane ${ }^{1 *}$ D, Deepak Gupta ${ }^{1}$, Tushar Parmar $^{2}$, Suvadeep Sen², Balakrishna Nimavat ${ }^{2}$, \\ Asawari Ambekar ${ }^{3}$ and Aabha Nagral ${ }^{1}$
}

\begin{abstract}
Background: Typhoid fever can manifest with a variety of gastrointestinal symptoms. However, in the present-day era, gastrointestinal bleeding related to bowel ulceration is becoming increasingly sporadic especially in the urban setting.

Case presentation: We present a rare case of life-threatening gastrointestinal bleeding from a typhoid ileal ulcer that was successfully managed with endoscopic therapy.

Conclusion: Though rare, this infective cause of gastrointestinal bleeding should still be considered in differential diagnosis, especially in developing countries.
\end{abstract}

Keywords: Typhoid fever, Gastrointestinal bleeding, Endoscopy, Sclerotherapy, Salmonella typhi

\section{Background}

Salmonella typhi and Salmonella paratyphi A, B, C cause typhoid and paratyphoid fever respectively. Gastrointestinal ulcers and bleeding, intestinal perforation, pancreatitis and cholecystitis are rare gastrointestinal complications of typhoid fever. Severe gastrointestinal bleeding occurs in $2 \%$ of cases and is associated with significant morbidity and mortality. With the advancement of endoscopic techniques, selected cases can be effectively salvaged. We present a rare case of severe gastrointestinal bleeding from a typhoid ileal ulcer which was managed successfully with prompt endoscopic intervention.

\section{Case presentation}

A 35-year-old gentleman from an urban city in India presented with complaints of fever for 2 weeks and passage of maroon-coloured stools for 4 days. He also complained of diffuse crampy abdominal pain. Fever was intermittent, low grade and not associated with chills or

\footnotetext{
* Correspondence: amey_max@yahoo.com

${ }^{1}$ Department of Gastroenterology, Apollo Hospitals, Navi Mumbai, India

Full list of author information is available at the end of the article
}

rigours. He also had shortness of breath, giddiness and easy fatiguability. There was no history of hematemesis, nausea or vomiting. He had no medical comorbidities or addictions and his family history was non-significant.

In the Emergency Room, he was febrile, had tachycardia and was hypotensive. He appeared pale and had a toxic look. Abdominal examination revealed mild tenderness over the right iliac fossa on deep palpation. A per-rectal examination revealed haematochezia. Respiratory and neurological examination was normal. He was immediately volume resuscitated using two large bore intravenous access lines. He was shifted to the intensive care unit and was started on inotrope support.

His laboratory parameters revealed haemoglobin of $6.5 \mathrm{~g} / \mathrm{dl}(13-18 \mathrm{~g} / \mathrm{dl})$, total leucocyte count of 8120 cells/ dl (4000-11,000 cells/dl) with $75 \%$ neutrophils and a normal platelet count. Renal functions revealed a serum creatinine value of $1.7 \mathrm{mg} / \mathrm{dl}(0.7-1.3 \mathrm{mg} / \mathrm{dl})$ and normal serum electrolytes. Liver function tests revealed a normal total serum bilirubin and elevated alanine and aspartate transaminase values [SGPT - $102 \mathrm{IU} / \mathrm{L}(5-45 \mathrm{IU} / \mathrm{L})$ and SGOT $-55 \mathrm{IU} / \mathrm{L}$ (5-40 IU/L) respectively]. Creactive protein was $16.3 \mathrm{mg} / \mathrm{L}(0-5 \mathrm{mg} / \mathrm{L})$. Indirect

\section{Springer Open}

(0) The Author(s). 2020 Open Access This article is licensed under a Creative Commons Attribution 4.0 International License, which permits use, sharing, adaptation, distribution and reproduction in any medium or format, as long as you give appropriate credit to the original author(s) and the source, provide a link to the Creative Commons licence, and indicate if changes were made. The images or other third party material in this article are included in the article's Creative Commons licence, unless indicated otherwise in a credit line to the material. If material is not included in the article's Creative Commons licence and your intended use is not permitted by statutory regulation or exceeds the permitted use, you will need to obtain permission directly from the copyright holder. To view a copy of this licence, visit http://creativecommons.org/licenses/by/4.0/. 
hemagglutination assay for amoebiasis was negative. After transfusion on 2 packed red blood cells, he underwent an emergent upper gastrointestinal endoscopy which was normal. After a gentle colonic purge, a colonoscopy was performed. Colonoscopy revealed multiple shallow ulcers of varying sizes in caecum, ileo-caecal valve and terminal ileum (Fig. 1). A large ulcer with mild oozing of blood was seen in the terminal ileum (Fig. 2). Multiple biopsies were taken from the ulcer base and edges. Careful irrigation of the ulcer base was performed to rule out an underlying visible vessel. After local sclerotherapy with diluted saline adrenaline (1:20,000 dilution), the ooze stopped. There was presence of blood mixed with liquid stools throughout the colon. Post procedure, he stabilized hemodynamically and haematochezia settled. There was no further drop in haemoglobin. A computerized tomogram of the abdomen revealed mildly dilated small bowel loops with minimal mucosal thickening and enhancement at caecum and ileo-caecal junction. Few sub-centimetre lymph nodes were seen along the mesentery located in the right iliac fossa. He was later shifted out of the intensive care unit.

Blood culture revealed a rich growth of nalidixic acid-resistant Salmonella typhi. Histopathology from the ulcer base revealed proliferating blood vessels and fibrocollagenous tissue with extensive acute inflammatory cell infiltrate. Necrotic tissue mixed with gram-negative bacterial colonies was observed (Fig. 3). Gene X-pert for Mycobacterium tuberculosis was negative on the tissue sample. He was continued on sensitive antibiotics (intravenous ceftriaxone) and discharged after a week on oral azithromycin. At follow-up after 4 weeks, he was stable and had resumed his job.

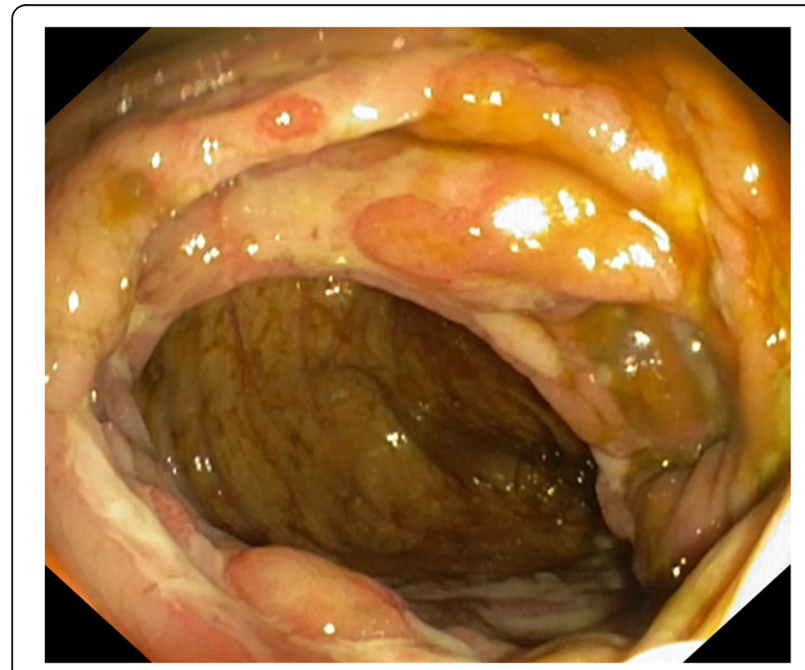

Fig. 1 Colonoscopy revealing multiple ulcers in caecum and over ileo-caecal valve

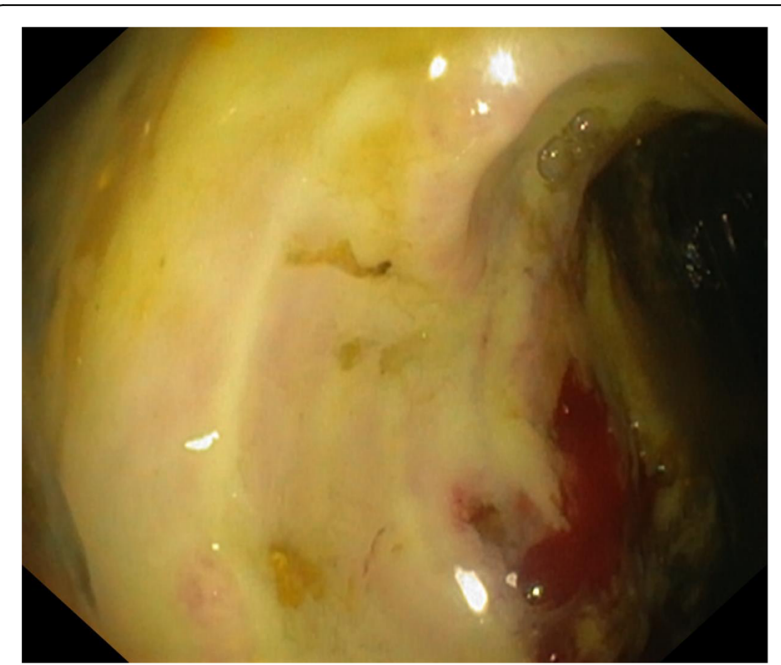

Fig. 2 Colonoscopy revealing a large terminal ileal ulcer with active oozing of blood

\section{Discussion}

The term enteric fever includes typhoid and paratyphoid fevers. Salmonella typhi, a gram-negative enteroinvasive bacterium causes typhoid fever, whereas paratyphoid fever is caused by Salmonella paratyphi A, B, C. Humans are the only natural host reservoirs, and the infection is transmitted by ingesting contaminated food or water. Upon ingestion, the bacteria invade the mucosa of small bowel and multiply in the reticuloendothelial tissues through a lymphatic/haematogenous access. Classical presenting features include fever, diffuse abdominal pain and tenderness, anorexia, weight loss and diarrhoea. Gastrointestinal haemorrhage, bowel perforation, peritonitis, endocarditis and myocarditis are rare complications. Other atypical manifestations of typhoid fever

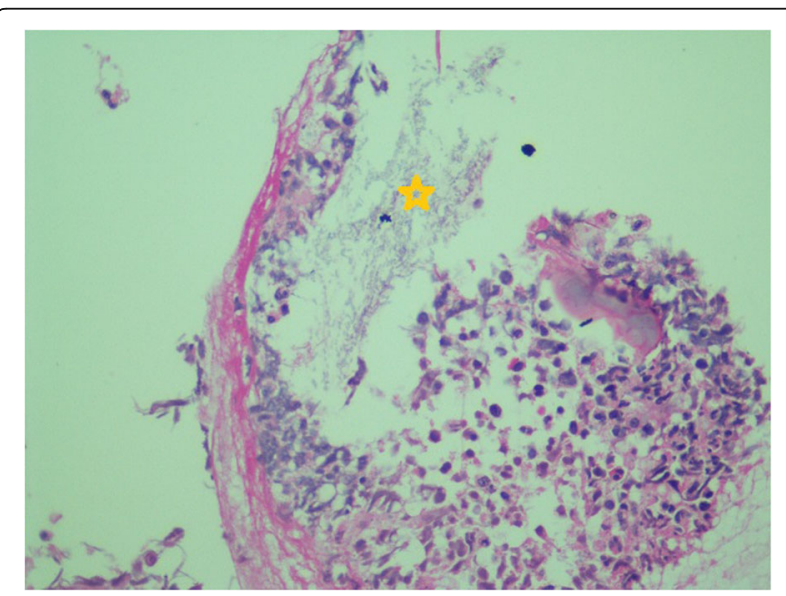

Fig. 3 Histopathology image from ulcer margin tissue demonstrating necrotic tissue with bacterial colonies (yellow star) 
include pneumonia, urinary symptoms, Guillain-Barre syndrome, pancreatitis, meningitis, osteomyelitis and orchitis. The diagnosis is typically made by a positive blood culture. Third-generation cephalosporins are recommended for first-line treatment. Azithromycin is a preferred alternative agent in uncomplicated enteric fever. Other supportive measures include oral or intravenous hydration, antipyretics, adequate nutrition, correction of dyselectrolytemia and blood transfusions for anaemia [1].

Gastrointestinal complications of enteric fever include gastrointestinal ulcers and bleeding, intestinal perforation, hepatic dysfunction, pancreatitis and cholecystitis. Hepatic dysfunction (transaminitis, elevated serum bilirubin and raised prothrombin time) is usually seen in severe infections and results from septicaemia, hepatocyte injury and associated malnutrition [2]. Active infection is commonly seen in terminal ileum due to the abundance of Peyer's patches followed by ileo-caecal valve, ascending and transverse colon. On colonoscopy, typhoid fever-related gastrointestinal ulcers appear as multiple, ovoid, variable-sized punched out lesions. The edges are soft, swollen and irregular [3]. Intestinal perforation occurs commonly near the ileo-caecal valve, where the ulcers become deeper than elsewhere [4]. Surgical intervention may be required to manage intestinal perforation, acalculous cholecystitis, perforation of gallbladder and gangrene of the intestine. The most serious complication seen in severe and untreated cases is intestinal perforation which occurs with the rate ranging between 0.6 and $4.9 \%$ across the world and classically presents with fever, abdominal pain and distension, dehydration, shock and sepsis [5].

Gastrointestinal bleeding (GIB) is observed in 10\% of cases. It is usually mild; however, significant GIB requiring blood transfusions is seen in $2 \%$ of these cases [6]. GIB occurs in the third week of the disease and is most commonly secondary to an ileal ulcer which causes necrosis in the wall of the small bowel. Massive life-threatening GIB is very rare, although seen occasionally. It has now become even more infrequent, especially in the urban setup due to the rampant use of antibiotics for fever. In a recent study, out of 1632 colonoscopies, only 104 patients had ileo-caecal region ulcers. Out of these, only 4 cases had ulcers related to typhoid fever [7].

Massive GIB usually presents with hypotension. A majority of typhoid ulcer bleeds are managed conservatively $[8,9]$, except in cases of massive life-threatening bleeding where urgent treatment becomes warranted. Endoscopic techniques are now emerging as the standard of care for managing active GIBs. Management options include adrenaline injection, thermal coagulation and application of hemoclips (in the presence of an underlying visible vessel) either alone or in combination [10-12]. A combination of the above techniques is preferred over a single technique as it reduces the rate of re-bleed. Adrenaline injection provides a tamponade effect and helps to achieve haemostasis. However, this effect is temporary and the chance of re-bleed is often high. In our case, since the bleeding had reduced to ooze and there was no evidence of an underlying visible vessel, the patient could be salvaged with diluted saline adrenaline injection as a standalone therapy. As the intestinal wall becomes thin and friable due to an ulcer formation, there is a theoretical risk of perforation associated with the endoscopic procedures [12]. At times, when it becomes difficult to identify a bleeding source endoscopically, angiographic super-selective coil embolization of bleeding vessel can be attempted [13]. Furthermore, in cases where endoscopy and interventional radiology fails to control massive GIB, surgery may be needed (segmental resection or hemicolectomy).

\section{Conclusion}

Literature regarding success of endoscopic therapy in typhoid ulcer-related GIB is rare with very few cases reported worldwide. In the pre-antibiotic era, typhoid ulcers were common; however, their occurrence has declined due to the indiscriminate use of antibiotics. Furthermore, typhoid ulcer-related massive GIB has itself become a rare phenomenon in the urban setting. Nonetheless, this rare infective cause of GIB should still be considered in differential diagnosis.

\section{Abbreviations}

GIB: Gastrointestinal bleeding; SGOT: Serum glutamic oxaloacetic transaminase; SGPT: Serum glutamic pyruvic transaminase

\section{Acknowledgements}

There are no acknowledgements.

\section{Authors' contributions}

AS, DG, SS and BN designed the case report, collected data, analysed it and drafted the manuscript. AA provided histopathological diagnosis and pictures. TP and AN reviewed the manuscript for technical errors and substantially revised it. All authors have read and approved the final manuscript.

\section{Funding \\ The original case report does not have any financial support for the manuscript or any potential financial funding.}

\section{Availability of data and materials}

All data generated or analysed during this study are included in this published article.

\section{Ethics approval and consent to participate}

Ethics approval and consent to participate has been obtained. Institutional Ethics Committee - Biomedical and Health Research, Apollo Hospitals, Navi Mumbai. Dated 15.04.20; reviewed and approved. Members: Dr. Santosh Kumar Jaiswal, Chairperson; Mrs. Pooja Lakhani, Member Secretary; Dr. Jahas J, Basic Medical Scientist, Dr. Shyam Shrivastav, Clinician (Scientific); Dr. Mini Nampoothiri Clinician (Scientific); Dr C N Chaudhary, Clinician (Scientific); Mr. Sayed Amjad Kadri, Legal Expert; Ms. Sujata Ashtekar, Social Scientist; Mr. Ganeshan Sundaram, Lay person (NonScientific); Mr. Gopalan Natarajan Lay person (Non-Scientific). 


\section{Consent for publication}

A written informed consent to publish information was obtained from the study participant.

\section{Competing interests}

The original case report does not have any conflict of interests.

The content of the manuscript has not been published, or submitted for publication elsewhere.

The manuscript is not for any particular special issue.

\section{Author details}

'Department of Gastroenterology, Apollo Hospitals, Navi Mumbai, India.

2Department of Intensive Care, Apollo Hospitals, Navi Mumbai, India.

${ }^{3}$ Department of Pathology, Apollo Hospitals, Navi Mumbai, India.

Received: 29 April 2020 Accepted: 18 June 2020

Published online: 21 July 2020

\section{References}

1. Upadhyay R, Nadka MY, Muruganathan A, Tiwaskar M, Amarapurkar D, Banka NH et al (2015) API recommendations for the management of typhoid fever. J Assoc Physicians India 63:77-96

2. Khan M, Coovadia YM, Karas JA et al (1999) Clinical significance of hepatic dysfunction with jaundice in typhoid fever. Dig Dis Sci 44:590-594

3. Reyes E, Hernández J, González A (1986) Typhoid colitis with massive lower gastrointestinal bleeding. An unexpected behavior of Salmonella typhi. Dis Colon Rectum 29:511-514

4. Bitar RE, Tarpley J (1985) Intestinal perforation in typhoid fever: a historical and state-of-the-art review. Rev Infect Dis 7:257-271

5. Jemni L, Mehdi A, Chakroun M et al (1989) Complications of typhoid fever. Med Trop (Mars) 49:189-191

6. Ezzat RF, Hussein HA, Baban TS (2010) Typhoid ulcer causing lifethreatening bleeding from Dieulafoy's lesion of the ileum in a seven-yearold child: a case report. J Med Case Rep 4:171

7. Toshniwal J, Chawlani R, Thawrani A, Sharma R, Arora A, Kotecha HL et al (2017) All ileo-cecal ulcers are not Crohn's: changing perspectives of symptomatic ileocecal ulcers. World J Gastrointest Endosc 9(7):327-333

8. Goel A, Bansal R (2017) Massive lower gastrointestinal bleed caused by typhoid ulcer: conservative management. Euroasian J Hepato-Gastroenterol 7(2):176-177

9. Boopathy V, Periyasamy S, Alexander T, Balasubramanian P. Typhoid fever with caecal ulcer bleed: managed conservatively. BMJ Case Rep. 2014;31: bcr2014203756.

10. Lee JH, Kim JJ, Jung JH et al (2004) Colonoscopic manifestations of typhoid fever with lower gastrointestinal bleeding. Dig Liver Dis 36:141-146

11. Wang H, Dong XL, Yu XM, Chung KS, Gao JP (2015) Successful endoscopic hemoclipping of massive lower gastrointestinal bleeding from paratyphoid A fever. World I Gastroenterol 21(3):1040-1043

12. Cho J (2019) Successful endoscopic hemoclipping and conservative management for typhoid fever complicated by massive intestinal bleeding and acute pancreatitis Case report. Medicine 98:31

13. Hart JL, Jackson JE (2008) Life-threatening colonic haemorrhage in typhoid fever: successful angiographic localization and platinum microcoil embolization of several sources. Clin Radiol 63:727-730

\section{Publisher's Note}

Springer Nature remains neutral with regard to jurisdictional claims in published maps and institutional affiliations.

\section{Submit your manuscript to a SpringerOpen ${ }^{\circ}$ journal and benefit from:}

- Convenient online submission

- Rigorous peer review

- Open access: articles freely available online

- High visibility within the field

- Retaining the copyright to your article

Submit your next manuscript at $\boldsymbol{\nabla}$ springeropen.com 